Article

\title{
Integrating Field Experiments with Modeling to Evaluate the Freshwater Availability at Ungauged Sites: A Case Study of Pingtan Island (China)
}

\author{
Xiaocong Liu ${ }^{1,2}{ }^{\mathbb{D}}$, Zhonggen Wang ${ }^{1, *}$, Yin Tang ${ }^{1}$, Zehua $\mathrm{Wu}^{3}$, Yuhan Guo ${ }^{1,2}$ \\ and Yashan Cheng ${ }^{1,2}$ \\ 1 Key Laboratory of Water Cycle and Related Land Surface Processes, Institute of Geographic Sciences \\ and Natural Resources Research, Chinese Academy of Sciences, Beijing 100101, China; \\ liuxc.14b@igsnrr.ac.cn (X.L.); tangyin@igsnrr.ac.cn (Y.T.); guoyh.16b@igsnrr.ac.cn (Y.G.); \\ chengyashan77@163.com (Y.C.) \\ 2 University of Chinese Academy of Sciences, Beijing 100049, China \\ 3 Fujian Research Institute of Water Conservancy and Hydropower, Fuzhou 350001, China; wzh0299@126.com \\ * Correspondence to: wangzg@igsnrr.ac.cn
}

Received: 7 May 2018; Accepted: 30 May 2018; Published: 6 June 2018

\begin{abstract}
Predictions in ungauged basins (PUB) has been always a focus of hydrological research. The problem presented by ungauged basins is how to reasonably estimate water resource availability. To solve the issues of data scale, this study combines field experiments and hydrological models to estimate freshwater availability in a typical ungauged sea island located in southeastern China. The free parameters in the hydrological model were derived from the point-scale rainfall-runoff experiments rather than calibration using river discharge observations. The rainfall-runoff experiments were performed on six sites covering 11 land cover types. Model validation at a sub-catchment showed that the combined method could successfully reproduce monthly streamflow, with a Nash-Sutcliffe Efficiency of 0.82 , correlation coefficient of 0.85 , and flow volume error of $6.5 \%$. The simulation results indicate high heterogeneity and distinct seasonal dynamics in freshwater availability across the entire island. This pioneering PUB study for Chinese islands could provide reference for planning and management of freshwater in a water shortage area.
\end{abstract}

Keywords: PUB; rainfall-runoff experiments; distributed hydrological model; Hydro-Informatic Modelling System (HIMS); freshwater availability

\section{Introduction}

China has been implementing a national strategy called the Belt and Road Initiative, where the "Belt" stands for the Silk Road Economic Belt and the "Road" stands for the 21st Century Maritime Silk Road. The development of the costal islands is an important part of the 21st Century Maritime Silk Road. There are numerous islands off the continent along the coastline, and most of them suffer from fresh water resource shortages and a lack of hydrologic monitoring. How to make a scientific assessment of available water resources in these ungauged islands is not only a forefront of hydrology research, but also a basic issue of reasonable exploitation and the utilization of water resources.

Predictions in ungauged basins (PUB) has always been a frontier and focus [1]. In the beginning of the 21st century, the International Association of Hydrological Sciences (IAHS) began an initiative of PUB focused on reducing the uncertainty in hydrological models and hydrological forecasts [2]. Many studies have been conducted since then, including hydrological simulation and parameter optimization for data acquisition methods [3-7]. Among this research, distributed hydrological 
models have been widely used in hydrological process simulations in ungauged basins due to their multi-resource information processing.

The problem presented by the ungauged basins in the utilization of water resources is how to evaluate the regional water resource scientifically and reasonably. Conventional methods for calculating water resources generally consider the total amount based on data from stations, which is difficult to implement in areas where there are no data, and the lumped total estimate cannot clarify the spatial distribution of water resources. Additionally, conventional water resource assessments only include liquid water such as surface water and groundwater, known as blue water [8]. However, the blue water only represents one-third of the freshwater resources if rainfall is taken as the original source of freshwater, since rainfall is converted eventually into three parts-surface water, soil water and groundwater-through hydrological processes such as vegetation interception, infiltration, runoff generation, and confluence $[9,10]$.

The importance of soil water as a part of the water resource was recognized during the 19th century [11], and it has been an important starting point for alleviating the global water crisis in recent years [12], especially in an agricultural country like China. Therefore, a scientific evaluation of water resources needs to consider unconventional water resources such as soil water, based on the water cycle process. However, the definition of soil water resources has not been fully unified [13]. The authors refer to the renewable soil water in the unsaturated zone recharged by natural sources (including precipitation, condensed water, and submersion), which can be used by vegetation and has a certain effect on maintaining a stable circle of the natural ecological environment $[14,15]$.

Many studies have been conducted on the estimation and evaluation of soil water resources, and corresponding calculation methods attained from farmland [9,10] and regional scales [13]. The main methods are based on the principle of water balance [16], although there are no widely used evaluation models. Regional-scale assessment of soil water resources can use hydrological models, especially distributed models, to simulate the spatial and temporal distribution, which can be combined with the estimation of surface water resources and groundwater resources to evaluate the total water resource [17].

However, not all of the water can be extracted to serve the water supply. Research needs to consider the water requirements of ecosystems that rely on freshwater [18]. It is necessary to ensure the sustainable state of the ecosystems when estimating freshwater availability. Additionally, the use of water resources in a region is also limited by the conditions of contemporary engineering measures, especially flood control during the flood season. Therefore, for the foreseeable period, abandoned floodwaters that cannot be controlled by engineering measures are difficult for localities to use, and should be deducted from the total water resource availability.

This study selected Pingtan Island in southeast China as the study area, which is the fifth-largest island in China, and is one of the starting points of the 21st Century Maritime Silk Road [19]. The ungauged island is suffering from a freshwater shortage, and the freshwater availability in space and time is not clear due to a lack of hydrological observations. The existing studies of the freshwater on the entire island are lacking fine spatial and temporal distribution due to a dependence on measured streamflow data, and the evaluation object is only surface and ground water. This work intends to reveal the freshwater availability, including soil water availability, by integrating field experiments with modeling, and provide a basis for future freshwater resource management on this ungauged island.

Against this background, the main objective of this study is to provide a basis for future freshwater resource management in Pingtan and a pattern to assess available freshwater in ungauged areas. The temporal and spatial distribution of freshwater availability in Pingtan Island will be estimated by integrating field experiments with modelling.

To satisfy the objectives of this study, the authors managed to get the spatial distribution of rainfall-runoff relation by ArcGIS based on field investigation and field rainfall-runoff experiments. Then, a distributed hydrological model of the island based on HIMS (Hydro-Informatic Modeling System) [20] was constructed and the model parameters were determined according to the spatial distribution of rainfall-runoff relation. Applying this distributed model, this study quantitatively 
determined the volumes of components of available water resources, temporally and spatially, with consideration of the environmental flow requirements and abandoned floodwater.

\section{Study Area and Data}

Pingtan Island is located in southeast China precisely between longitudes $119^{\circ} 40^{\prime} \mathrm{E}$ and $119^{\circ} 53^{\prime} \mathrm{E}$ and latitudes $25^{\circ} 23^{\prime} \mathrm{N}$ and $25^{\circ} 40^{\prime} \mathrm{N}$ (Figure 1a). The total area is $275.2 \mathrm{~km}^{2}$. There are undulating hills and low mountains in the south and north, and plains comprise the middle part. The average annual temperature is $19.8^{\circ} \mathrm{C}$ and the annual precipitation is $1236.1 \mathrm{~mm}$. Due to the impact of typhoons, the distribution of precipitation during the year is extremely uneven. The precipitation is generally the highest from March to June, while from July to September most of the precipitation is caused by typhoons. The surface layer of the island is mainly an aeolian layer, dominated by aeolian sand, and has strong infiltration capacity. The change of topography in the island is relatively small. The highest elevation is only $440 \mathrm{~m}$, and the overall surface water storage capacity is weak [21]. Owing to the restrictions of the topography and soil conditions, the water system of Pingtan Island is extremely underdeveloped. The streams are seasonal, and the surface water is very limited. Pingtan Island lacks hydrological monitoring stations.

This study collected the daily rainfall data, maximum and minimum temperature data of the only national meteorological station on the island (data are monitored by the Pingtan Meteorological Service, and are available at http:/ / data.cma.cn/), and the observed daily rainfall data of a rainfall station from 1986-2012 (data are monitored by the Hydrology and Water Resources Survey Bureau of Fujian Province). The authors also collected a set of observed monthly inflow data of the largest lake (36-Foot Lake, with a catchment area of $11.6 \mathrm{~km}^{2}$ ) on the island from the Hydrology and Water Resources Survey Bureau of Fujian Province, which were only used for model validation.

Based on the interpretation of a scene of remote sensing images from Landsta8 (https: / / earthexplorer. usgs.gov/), the land use has five categories: cultivated land (41.6\%), wood land (14.1\%), grass land $(18.0 \%)$, water $(5.5 \%)$, and construction land $(20.8 \%)$ (Figure $1 b)$. According to the national soil census data $(1: 50,000$, 1983), the soil is classified into three types: amorphic soil (54\%), ferralsol (37.8\%), and alkali-saline soil and others (8.2\%) (Figure 1c). According to the Second National Land Survey Technical Regulations of China [22], the slope derived from the DEM data (spatial resolution $2 \mathrm{~m} \times 2 \mathrm{~m}$, came from the Fujian Research Institute of Water Conservancy and Hydropower) is classified into four grades: $\left(0^{\circ}-6^{\circ}\right),\left(6^{\circ}-15^{\circ}\right)$, $\left(15^{\circ}-25^{\circ}\right),\left(25^{\circ}-88^{\circ}\right)$ (the slope in the island ranges from $0^{\circ}$ to $88^{\circ}$ ) (Figure $1 \mathrm{~d}$ ).
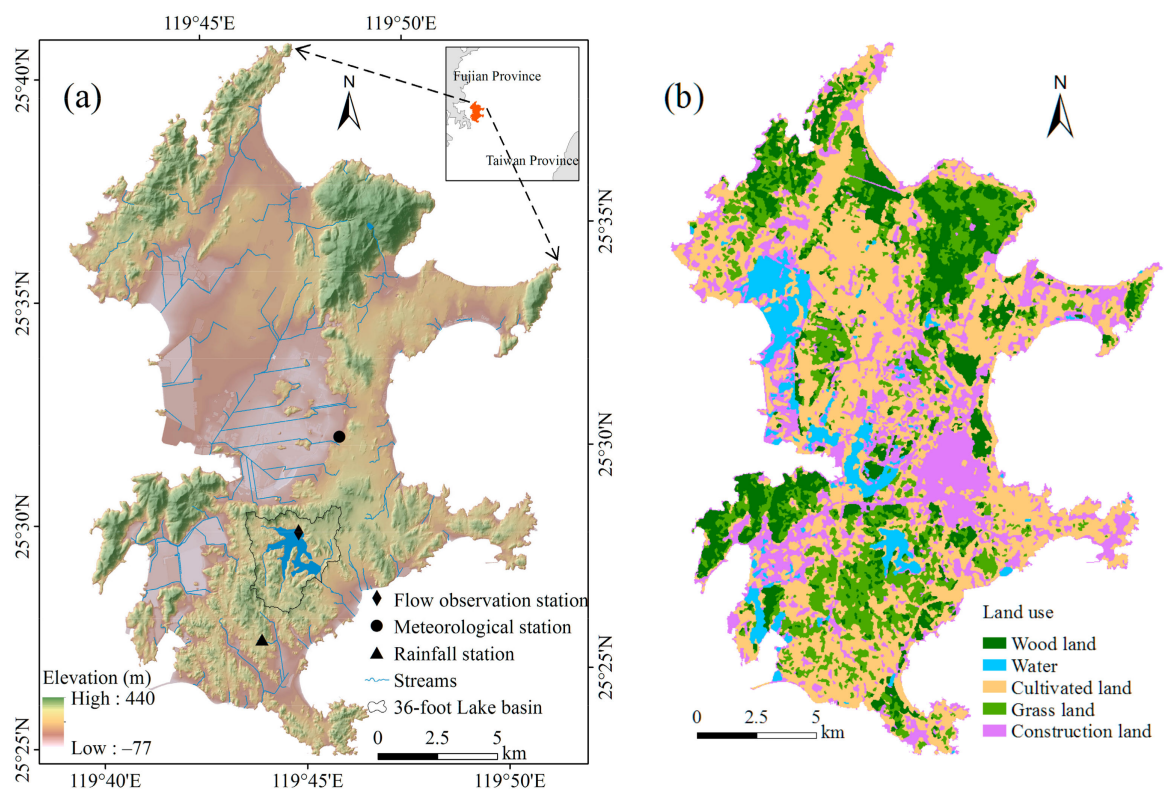

Figure 1. Cont. 

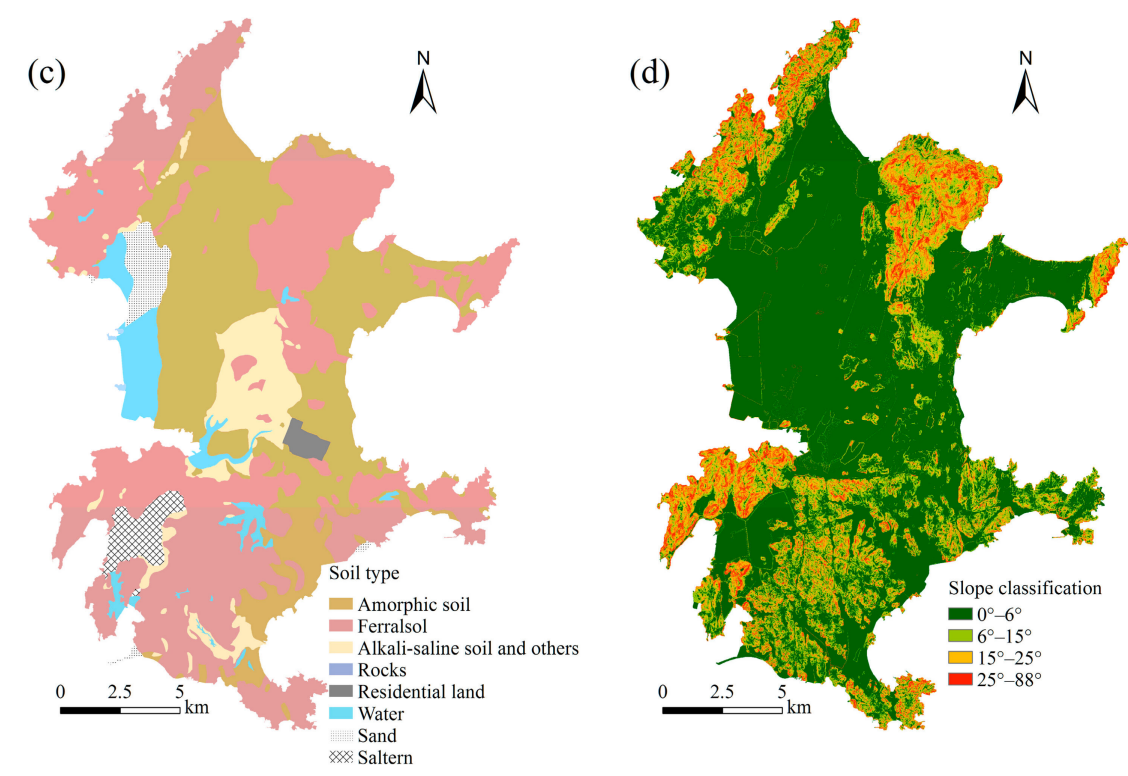

Figure 1. (a) The study area and location of meteorological and rainfall stations; (b) Spatial distribution of land use; (c) Spatial distribution of soil types; and (d) Map of slope classification.

\section{Methods}

\subsection{Field Rainfall-Runoff Experiments}

Due to the lack of hydrological monitoring data in Pingtan Island, this study carried out rainfall-runoff field experiments in order to understand the hydrological characteristics and provide a basis for the construction and parameter calibration of a HIMS model. Considering the main underlying surface factors affecting the runoff, this study first identified the typical types of underlying surface in the island, and then combined this information with a field survey to determine the experimental sites that could cover the typical underlying surfaces.

Among the land use types, the cultivated land runoff coefficient was nearly zero due to the sandy soil. The construction land runoff coefficient was high due to the high imperviousness degree, so its runoff coefficient was determined according to China's Code for the Design of Outdoor Wastewater Engineering [23] as 0.8. Thus, the grassland and woodland were left for field experiments. Subsequent to combining the woodland and grassland, soil, and the slope of the island, the underlying surface was classified into 24 types. Then, the poorly represented types (less than $1.5 \%$ of the area) were merged into those types which were similar, and the underlying surface was eventually classified into 11 types (Table 1). According to the field research, this study identified six representative experimental sites (Figure 2a). A $1 \mathrm{~m} \times 1 \mathrm{~m}$ field was set under different underlying surfaces in the experimental area, and a portable rainfall simulator device was applied [24], developed by the Institute of Geographic Sciences and Natural Resources Research (IGSNRR) in the Chinese Academy of Sciences (Figure 2b,c). The runoff volumes and duration were observed under different rainfall intensities $(150 \mathrm{~mm} / \mathrm{h}$, $200 \mathrm{~mm} / \mathrm{h}, 250 \mathrm{~mm} / \mathrm{h}, 300 \mathrm{~mm} / \mathrm{h}, 350 \mathrm{~mm} / \mathrm{h}$ ).

The artificial rainfall stopped when the runoff came to a stable state for a couple of minutes, and the runoff monitoring stopped when there was no runoff generated for each experiment. The runoff coefficient of each experiment was the ratio of total runoff to total rainfall, and the average runoff coefficient of each underlying surface was the mean of runoff coefficients under five rainfall intensities. The observed runoff coefficient was used for model calibration, and was used for generating the spatial distribution map of runoff coefficients in the study area, together with an ArcGIS spatial assignment and area-weighted statistics. Using ArcGIS, the authors joined the polygon-layer attribute table of the underlying surfaces with the runoff coefficients table, and then intersected this layer with the 
sub-basins layer. Underlying surfaces polygons inside each sub-basin could be identified based on the intersect result, and the comprehensive runoff coefficient of each sub-basin was determined from the area-weighted statistic of these polygons' runoff coefficients.

Table 1. Typical underlying surface types and their areas.

\begin{tabular}{ccc}
\hline No. & Typical Underlying Surface Type & Area $\mathbf{( k m}^{\mathbf{2}} \mathbf{)}$ \\
\hline 1 & Grassland + Ferralsol $+\left(6^{\circ}-15^{\circ}\right)$ & 13.86 \\
2 & Woodland + Ferralsol $+\left(15^{\circ}-25^{\circ}\right)$ & 11.25 \\
3 & Grassland + Amorphic soil $+\left(0^{\circ}-6^{\circ}\right)$ & 9.73 \\
4 & Woodland + Amorphic soil $+\left(0^{\circ}-6^{\circ}\right)$ & 10.81 \\
5 & Grassland + Ferralsol $+\left(15^{\circ}-25^{\circ}\right)$ & 10.04 \\
6 & Grassland + Ferralsol $+\left(0^{\circ}-6^{\circ}\right)$ & 8.65 \\
7 & Woodland + Ferralsol $+\left(6^{\circ}-15^{\circ}\right)$ & 8.15 \\
8 & Woodland + Ferralsol + $\left(25^{\circ}-88^{\circ}\right)$ & 5.96 \\
9 & Grassland + Ferralsol + $\left(25^{\circ}-88^{\circ}\right)$ & 3.90 \\
10 & Grassland + Alkali-saline soil and others $+\left(0^{\circ}-6^{\circ}\right)$ & 2.50 \\
11 & Woodland + Ferralsol $+\left(0^{\circ}-6^{\circ}\right)$ & 2.96 \\
\hline
\end{tabular}
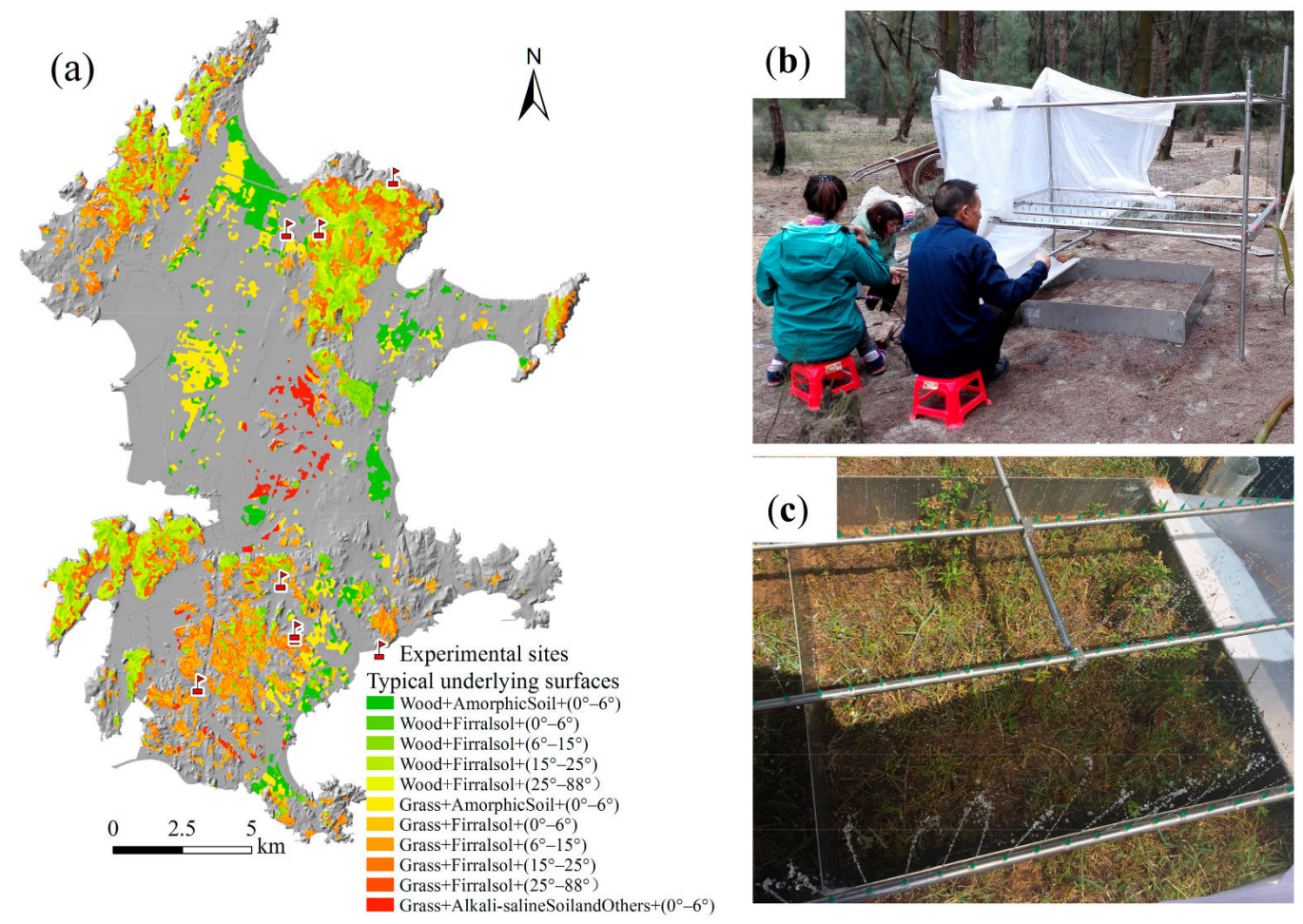

Figure 2. (a) Spatial distribution of underlying surface types and selected sites for the field rainfall-runoff experiments; (b) Conducting field experiments; and (c) A field site for experiments $(1 \mathrm{~m} \times 1 \mathrm{~m})$.

\subsection{Hydrological Modeling}

\subsubsection{HIMS Model and Input Data}

This study built a Pingtan Island distributed hydrological model based on HIMS [20,24]. This model is described briefly here, and further details can be found in Liu et al. (2008) [20]. The HIMS model is a distributed hydrological model for simulating the hydrological processes with appropriate hydrological modules for the study area. Its hydrological processes included interception, infiltration, evapotranspiration, snowmelt, surface runoff, sub-surface flow, and baseflow generation and concentration. It contains various 
choices of equations for each hydrological process and combines two runoff generation mechanisms of saturation excess and intensity excess.

The input data included time series data (meteorological and hydrological data) and spatial data. The spatial data input for modelling included land use data, soil data, and slope data. The rainfall data from the national meteorological station and the local rainfall station were interpolated into surface data with the Kriging method and then extracted to a sub-basin scale.

\subsubsection{Sub-Basin Division}

The plains in the middle of the island occupy $32 \%$ of the area of Pingtan Island, and the stream channels influenced by human alterations cannot characterize the catchments properly. Therefore, this study applied grids $(1 \mathrm{~km} \times 1 \mathrm{~km})$ rather than sub-basins in the plain area to make discretization, and the flow direction of each grid was determined according to actual river flow. The sub-basins' boundaries were derived from the DEM in the mountainous area and were set as the baseline when joining the grids of the plain area (Figure 3). Thus, the study area was divided into 286 sub-basins and grids in total, with 119 estuaries as shown in Figure 3.

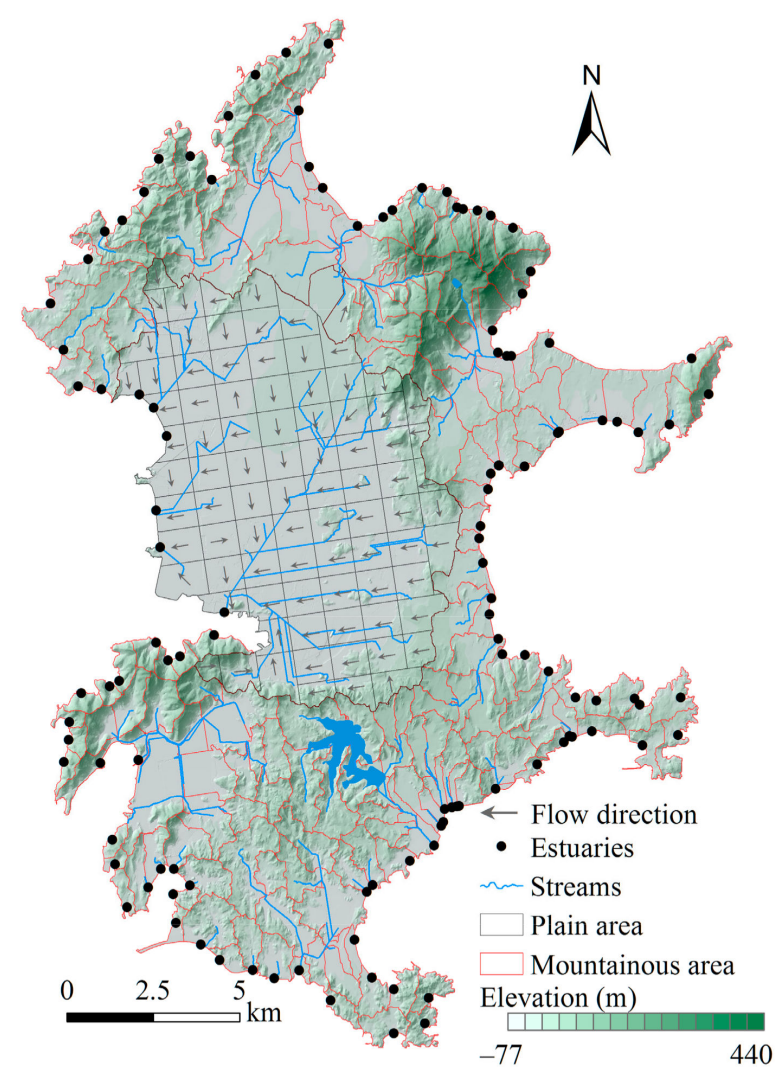

Figure 3. Discretization in the plain area with grids, the mountainous area with sub-basins, and the distribution of estuaries.

\subsubsection{Calibration and Validation}

The HIMS hydrological model was calibrated using local rainfall-runoff relations, and validated against monthly streamflow observation. Due to the lack of hydrological monitoring, the authors calibrated model parameters (Table A1 in Appendix A1) according to the comparison of rainfall-runoff relations between experimental results and simulations. According to the geological survey of local authorities, the groundwater is mostly shallow groundwater on Pingtan Island and is discharged into channels in the same basin, so we referred to this condition when calibrating the parameters. The model was validated at the 36-Foot Lake sub-basin by using the observed monthly streamflow 
data (1986-2012). The efficiency was evaluated by the Nash-Sutcliffe Efficiency (NSE), the flow volume error $(W E)$ and the correlation coefficient $(r)$.

$$
\begin{gathered}
N S E=1-\frac{\sum_{i=1}^{n}\left(Q_{o b s, i}-Q_{s i m, i}\right)^{2}}{\sum_{i=1}^{n}\left(Q_{o b s, i}-\overline{Q_{o b s}}\right)^{2}}, \\
W E=\frac{\sum_{i=1}^{n}\left(Q_{o b s, i}-Q_{s i m, i}\right)}{\sum_{i=1}^{n} Q_{o b s, i}} \cdot 100 \%, \\
r=\frac{\sum_{i=1}^{n}\left(Q_{o b s, i}-\overline{Q_{o b s}}\right)\left(Q_{s i m, i}-\overline{Q_{s i m}}\right)}{\sqrt{\sum_{i=1}^{n}\left(Q_{o b s, i}-\overline{Q_{o b s}}\right)^{2} \cdot \sum_{i=1}^{n}\left(Q_{s i m, i}-\overline{Q_{s i m}}\right)^{2}}},
\end{gathered}
$$

where $Q_{o b s, i}$ is the $i$ th observation, $Q_{\text {sim,i }}$ is the $i$ th simulated value, $\overline{Q_{o b s}}$ and $\overline{Q_{s i m}}$ are the means of observed data and simulated values, respectively, and $n$ is the number of datasets. NSE describes the fitting extent between simulation and observation datasets of streamflow and $r$ describes the correlation between simulated and observed streamflow. The simulating accuracy was high if NSE and $r$ were very close to 1 . The simulation performance was not good if NSE was close to 0 . The simulation accuracy was high if the absolute value of $W E$ was close to 0 . Generally, if WE was within the range of $\pm 10 \%$, the simulation results were regarded as satisfactory.

\subsection{Quantification of Freshwater Availability}

\subsubsection{Surface Water and Groundwater Availability}

Monthly surface and ground water were estimated using the summation of water yield and deep aquifer recharge in the model. The availability of this part of the water resource was calculated by subtracting the environmental flow requirement and flood discharge from the surface water.

This study assumed that precipitation in humid areas could meet the needs of the terrestrial ecosystem function outside the river, and thus only the environmental flow requirement in the river was considered. Moreover, the streams in the study area were seasonal and flowed into the sea independently. Therefore, to maintain the normal environment of estuaries, this study referred to the Tennant method [25] and took $20 \%$ of the average annual flows in flood season (April-September) and non-flood season (October-March) as the environmental flows.

The flood discharge was constrained by engineering measures such as ponds and reservoirs, which were useful to collect water during the flood season. This study assumed that these ponds and reservoirs could effectively collect floods, although many of them were not used due to a lack of management, according to our field survey. Thus, the flood discharge came from basins without water collection facilities. The annual monthly amount of flood discharge was determined based on the ratio of the annual monthly maximum flow to the multi-year average monthly flow [26].

\subsubsection{Soil Water Availability}

The soil water resource was calculated based on the methods of Feng [27] and Shen [15]. The amount of soil water resources within a period was:

$$
W_{s, t o t a l}=\sum_{i=1}^{n} W_{s, i}
$$

where

$$
W_{s, i}=E_{i}+T_{i}+\Delta W_{S R, i}
$$


$W_{s, t o t a l}$ is the total amount of soil water resource within a period; $i$ is the sub period from the start of the $i$ th rainfall to the start of the $(i+1)$ th rainfall within the period; $W_{s, i}$ is the soil water resource of the $i$ th sub period, $E_{i}$ is the soil evaporation, $T_{i}$ is the transpiration; and $\Delta W_{S R, i}$ is the soil water storage change.

Soil water availability refers to the renewable soil water that can be used by crops. All the soil water resources of agricultural land (cultivated land) were considered as available water resources because the evaporation and transpiration could be used by applying mulch or using greenhouses [28], while the woodland and grassland were regarded as part of the eco-environment with the main function of maintaining a good state of the environment and were unable to be arbitrarily changed. Therefore, their soil water resources were not included in the available water resource.

\subsubsection{Total Freshwater Availability}

The total freshwater availability for each basin in this study was the sum of the surface water availability, groundwater availability, and the soil water availability.

\section{Results and Discussion}

\subsection{Spatial Distribution of Runoff Coefficients Based on Field Experiments}

The runoff coefficients of typical underlying surfaces and the corresponding distribution in the island were obtained based on the rainfall-runoff experimental data (Table 2, and Figure 4a). The results showed the spatial heterogeneity of runoff coefficients. The grassland was relatively poor in surface water permeability, in terms of land use type, and its runoff coefficient was greater than that of forest. Regarding underlying surfaces, with the same land use type and the same slope classification in terms of soil type, the ferralsol types had the smallest runoff coefficients, while the Alkali-saline soil and others types had the largest. Concerning the slope classification, the larger the slope, the larger the runoff coefficient. The runoff coefficients based on field experiments in the study area ranged from 0.01 to 0.85 , and the overall runoff coefficient was 0.44 .
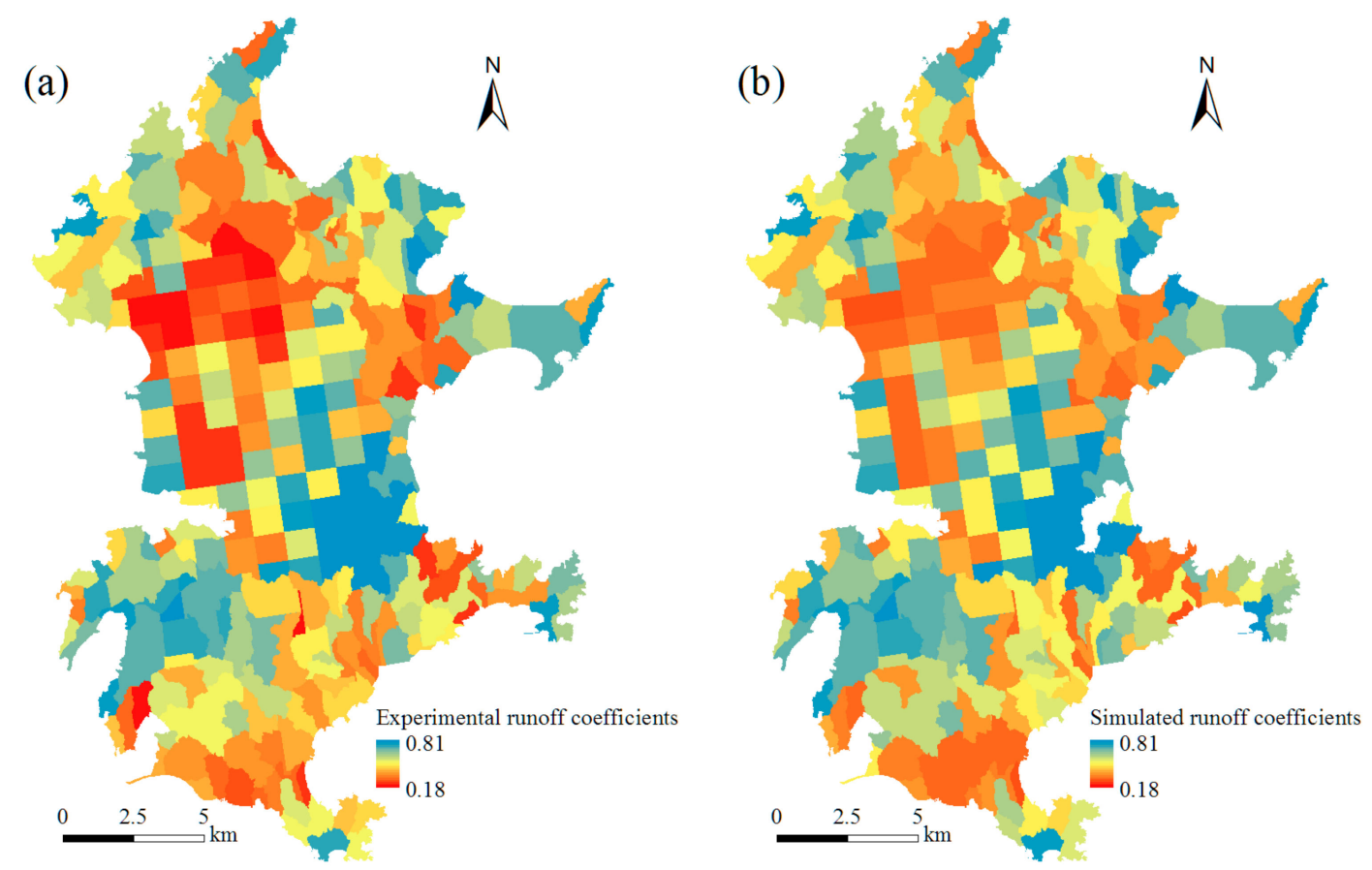

Figure 4. Spatial distribution of runoff coefficients derived from (a) field experiments and (b) HIMS (Hydro-Informatic Modeling System) model simulation. 
Table 2. Runoff coefficients of typical underlying surfaces based on field experiments.

\begin{tabular}{ccc}
\hline No. & Typical Underlying Surface Type & Runoff Coefficient \\
\hline 1 & Grassland + Ferralsol $+\left(6^{\circ}-15^{\circ}\right)$ & 0.72 \\
2 & Woodland + Ferralsol $+\left(15^{\circ}-25^{\circ}\right)$ & 0.13 \\
3 & Grassland + Amorphic soil $+\left(0^{\circ}-6^{\circ}\right)$ & 0.29 \\
4 & Woodland + Amorphic soil $+\left(0^{\circ}-6^{\circ}\right)$ & 0.25 \\
5 & Grassland + Ferralsol $+\left(15^{\circ}-25^{\circ}\right)$ & 0.80 \\
6 & Grassland + Ferralsol $+\left(0^{\circ}-6^{\circ}\right)$ & 0.59 \\
7 & Woodland + Ferralsol $+\left(6^{\circ}-15^{\circ}\right)$ & 0.08 \\
8 & Woodland + Ferralsol $+\left(25^{\circ}-88^{\circ}\right)$ & 0.14 \\
9 & Grassland + Ferralsol $+\left(25^{\circ}-88^{\circ}\right)$ & 0.85 \\
10 & Grassland + Alkali-saline soil and others $+\left(0^{\circ}-6^{\circ}\right)$ & 0.44 \\
11 & Woodland + Ferralsol $+\left(0^{\circ}-6^{\circ}\right)$ & 0.01 \\
\hline
\end{tabular}

\subsection{Calibration and Validation of HIMS Model}

This study completed the HIMS model calibration based on the comparison of the spatial distribution of runoff coefficients derived from the model simulation and field rainfall-runoff experiments. The simulated overall average runoff coefficient of the island was 0.41 , with only a $3 \%$ difference from the experimental results. Moreover, the runoff coefficients' spatial distribution of each sub-basin between the simulated and experimental results showed a good consistency, with an average error of 13\% (Figure 5). The HIMS model not only simulated the average runoff coefficient, but also accurately captured the spatial distribution of the runoff characteristics of the island.

A time series comparison between simulated and observed streamflows of 36-Foot Lake is shown in Figure 6. The $r$ was 0.85 , NSE was 0.82 , and WE was $6.5 \%$, which meant the HIMS model simulation was satisfactory in this sub-basin. The results showed that the parameters of the distributed HIMS model established by this method were reasonable and the HIMS model was suitable for the island and could be used for water resource estimation.

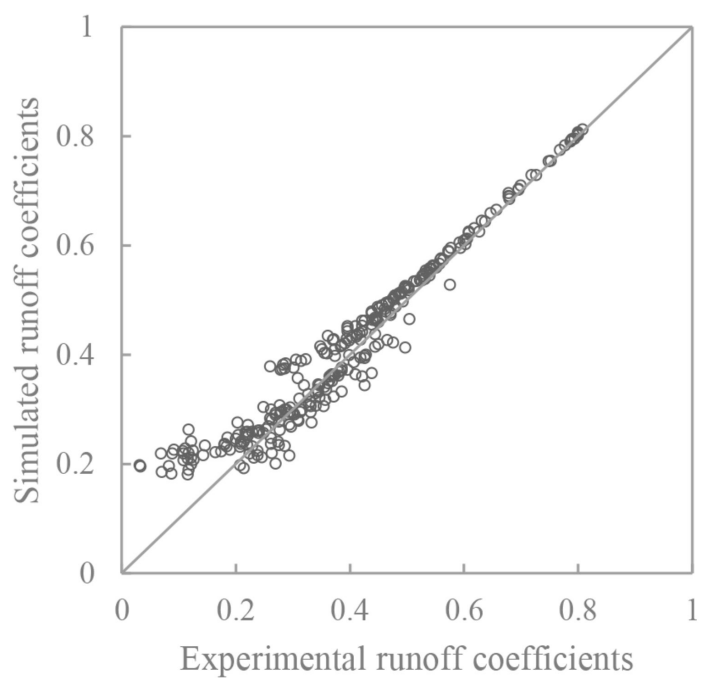

Figure 5. Comparison of sub-basin runoff coefficients between experimental and simulated values. 


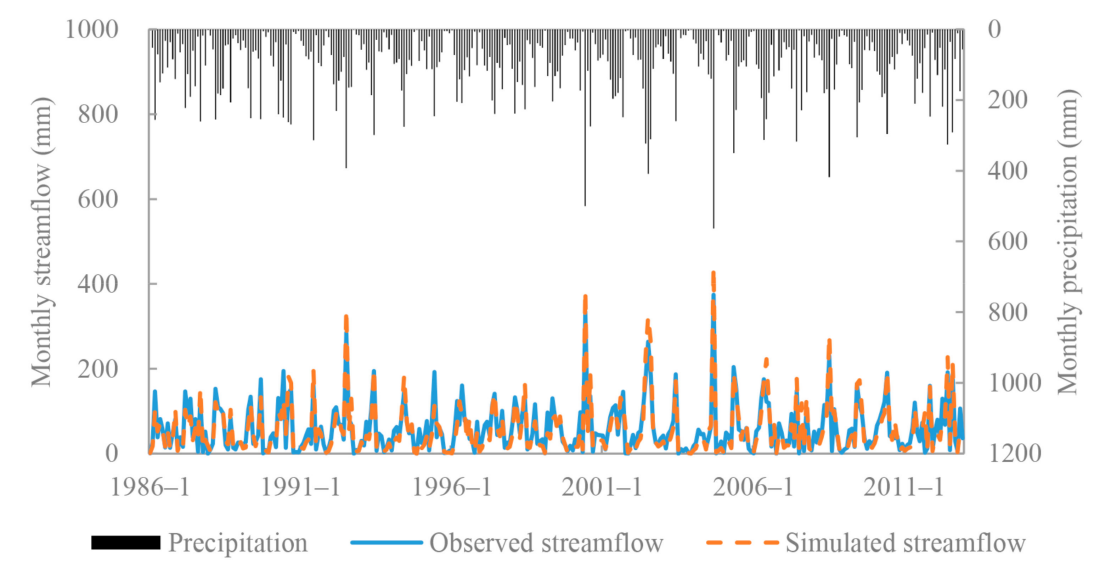

Figure 6. Comparison of monthly streamflows between measured and simulated values at 36-Foot Lake.

\subsection{Freshwater Availability}

\subsubsection{Surface Water and Groundwater Availability}

The mean annual (from 1986 to 2012) surface water and groundwater was $1.40 \times 10^{8} \mathrm{~m}^{3}$ (or $509 \mathrm{~mm}$ ) based on the HIMS model results, which was less than the mean annual $1.79 \times 10^{8} \mathrm{~m}^{3}$ (or $652 \mathrm{~mm}$ ) from the Fujian Province Water Resources Bulletin (from 2012 to 2016). The surface water and groundwater availability were $0.96 \times 10^{8} \mathrm{~m}^{3}$ (or $348 \mathrm{~mm}$ ) after cutting off the environmental flow and flood discharge.

Due to the strong weathering on the island, the rocks were loose and the surface soil sandy with strong infiltration, making runoff generation difficult when the rain intensity was low and the duration was short. According to the distribution within the year, the total surface and groundwater availability was concentrated from May to September (Figure 7a). Specifically, summer (June-August) was the highest of the four seasons, accounting for $45.22 \%$ of the whole year, followed by spring and autumn, while winter was the least, only $7.34 \%$ (Figure $7 \mathrm{~b}$ ).

The spatial distribution of annual surface and groundwater availability showed a spatial differentiation (Figure 8a). There was more water in the central and northern parts of the island than in the small watersheds scattered in the east, south, and on the edge of the island.

\subsubsection{Soil Water Availability}

The soil water availability in the study area is shown in Figures 7 and $8 \mathrm{~b}$. The mean annual availability was $0.74 \times 10^{8} \mathrm{~m}^{3}$ (or $269 \mathrm{~mm}$ ), which showed a considerable potential for agricultural water use, especially in water shortage areas. Unlike the surface and groundwater, the soil water availability was highest in spring, followed by summer, while autumn and winter were still the lowest. The proportions of soil water availability were higher than those of surface and groundwater availability during November to May, while the opposite was true during June to October. The soil water availability was higher in the central and northern plains and small parts in the southern area.

\subsubsection{Total Freshwater Availability}

The mean annual total freshwater availability was $1.70 \times 10^{8} \mathrm{~m}^{3}$ (or $617 \mathrm{~mm}$ ) on this island, and summer accounted for the highest proportion (39.71\%), followed by spring (31.18\%). Spatially, the central plain accounted for $0.60 \times 10^{8} \mathrm{~m}^{3}$, and the mountainous area accounted for $1.10 \times 10^{8} \mathrm{~m}^{3}$. The available freshwater resources were concentrated in the central plain and the intermountain basins on the inland of the island. The sub-basins around the island with short and dispersive flow channels had small streamflow, which are difficult to collect and use. Moreover, the plains and intermountain basins had good formation conditions for groundwater due to the distribution of loose rocks of aeolian deposits and marine deposits, and cultivated lands were concentrated in these areas. Thus, the total available freshwater resources in the plain area and the intermountain basins were larger than in the mountains. 

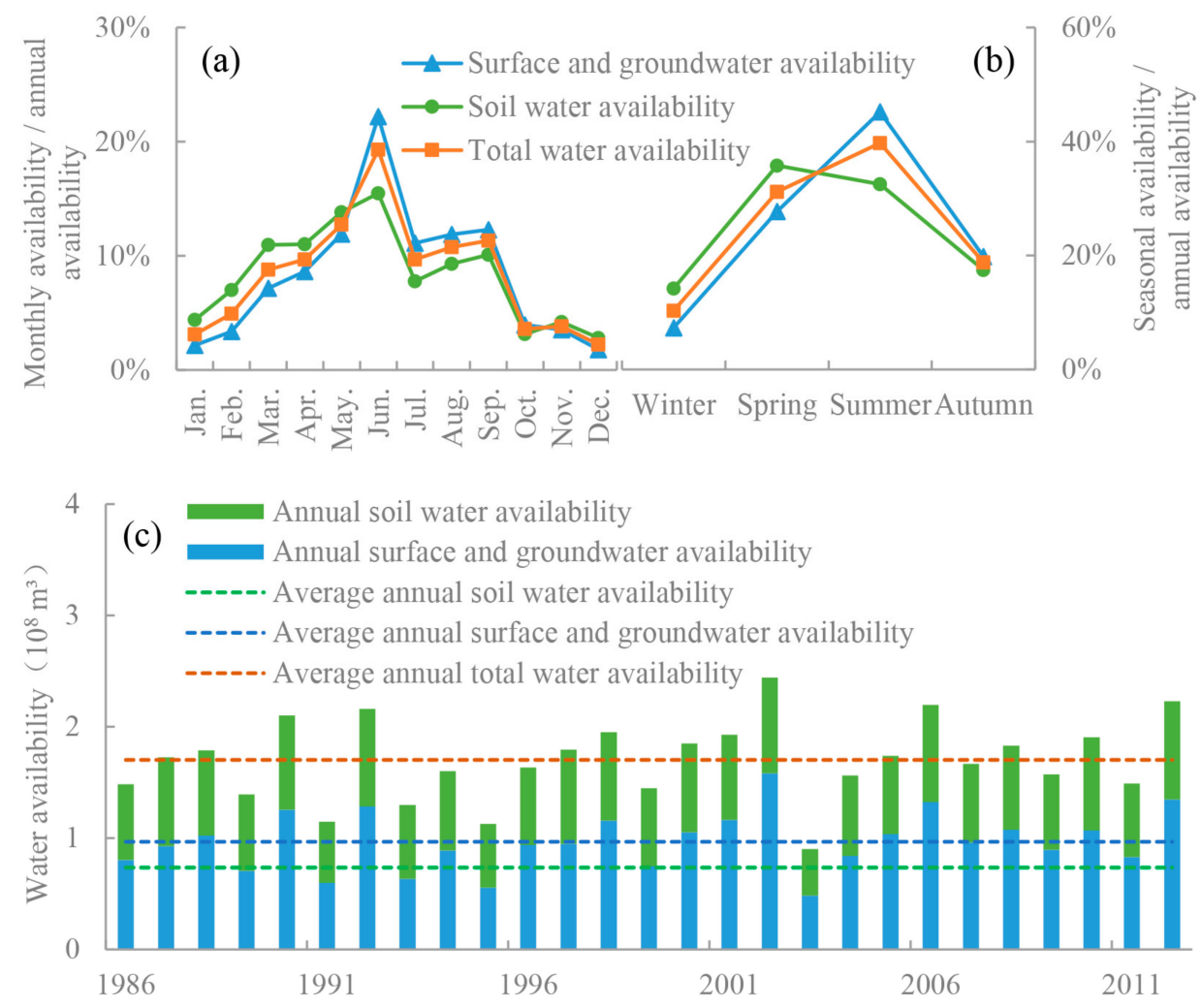

Figure 7. Temporal distribution of (a) monthly proportions of freshwater availability; (b) seasonal proportions of freshwater availability; and (c) yearly freshwater availability.
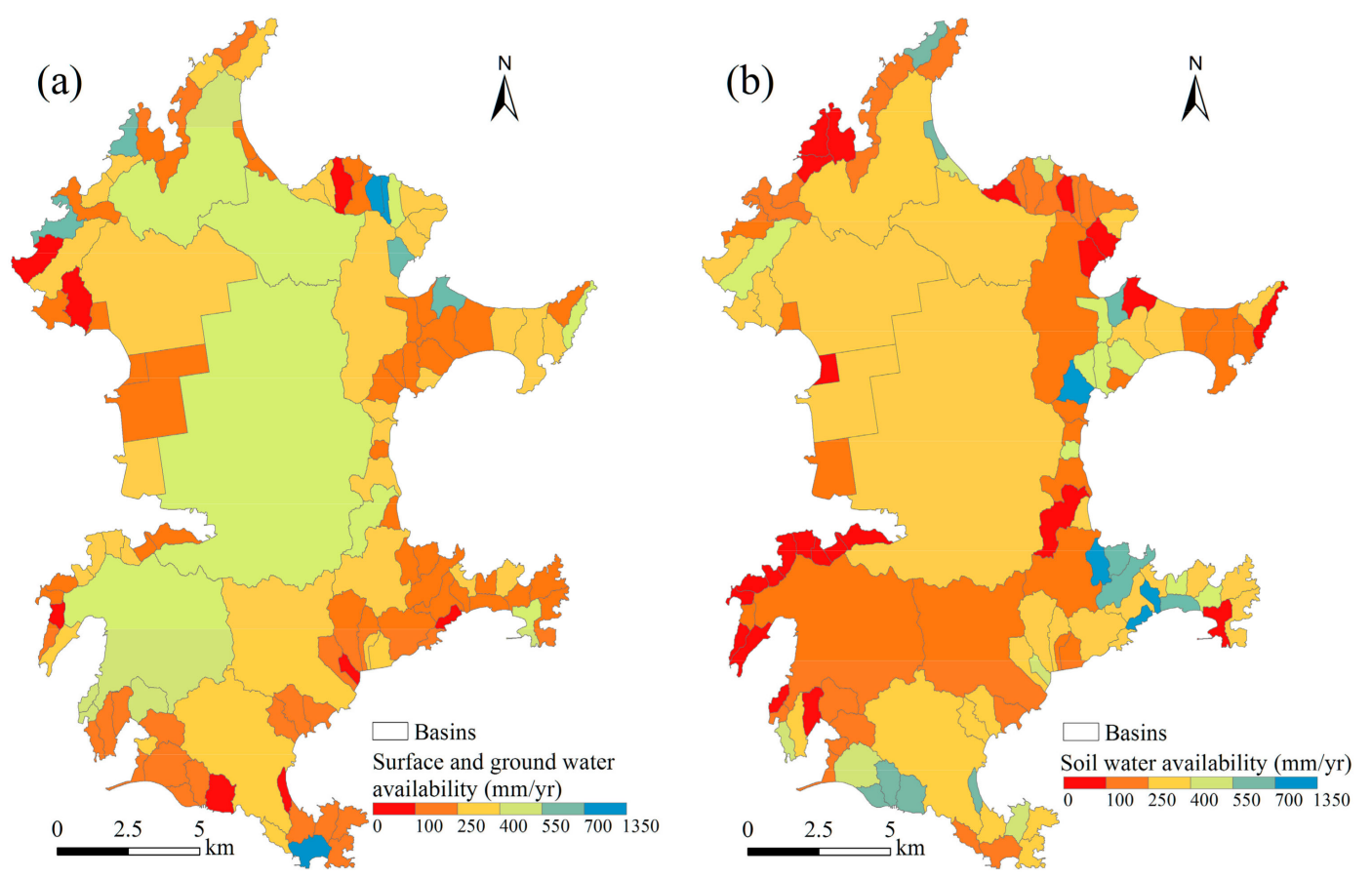

Figure 8. Cont. 


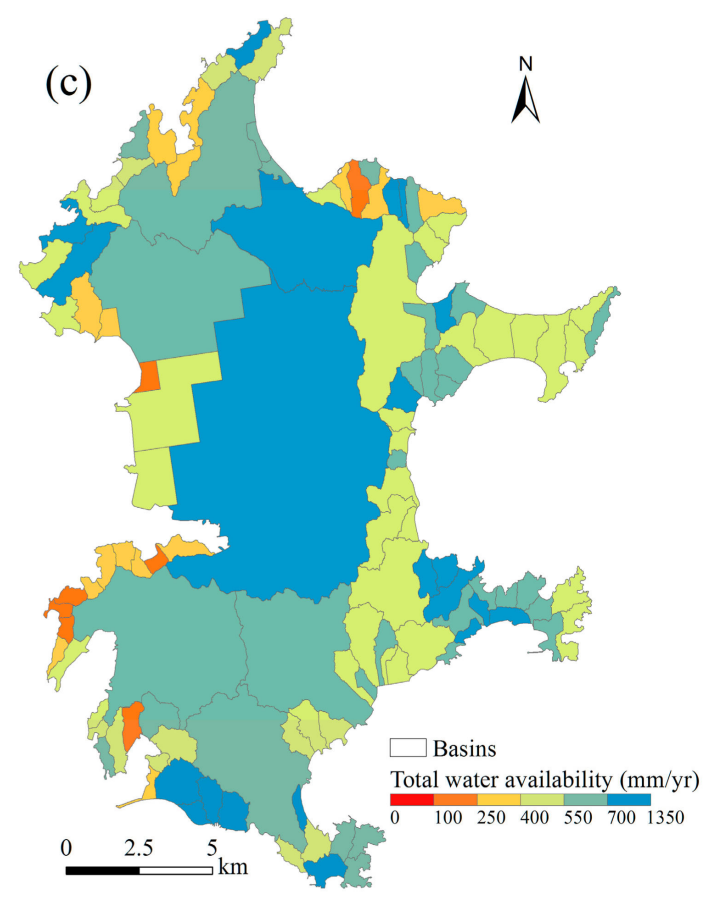

Figure 8. Spatial distribution of (a) surface and groundwater availability; (b) soil water availability; and (c) total freshwater availability.

\section{Conclusions}

This study provides a basis for freshwater management in Pingtan Island while demonstrating the spatial and temporal distribution of freshwater availability. Additionally, this work provides a method of estimating freshwater resources in an ungauged area. It showed good performance by using the rainfall-runoff relations derived from field experiments to calibrate the distributed hydrological model, and non-specific basin flow data to validate the model. Thus, freshwater resource distribution could be estimated based on the model output. Noteworthy are model parameter adjustments that referred to the local underlying surface and geological characteristics; for example, the groundwater was mostly shallow groundwater on Pingtan Island and discharged into channels in the same basin, according to the geological survey of local authorities.

The field experiment results revealed the spatial distribution of rainfall-runoff relations on ungauged Pingtan Island, with an overall runoff coefficient of 0.44 . The HIMS-based hydrological model constructed and calibrated based on experimental results showed good performance in the validation of sub-basin monthly data with an NSE of 0.82 . Results revealed the spatial heterogeneity and temporal characteristics of freshwater resources. Freshwater resources were concentrated in plains and intermountain basins rather than mountains and small basins around the island. The freshwater availability was concentrated from May to September within the year, and the highest availability proportions were in summer, spring, and summer for surface and groundwater, soil water, and the total freshwater resources, respectively. The temporal and spatial distribution of freshwater could provide references for local flood control and water supply management.

Author Contributions: X.L., Z.W., Z.W., Y.G. performed the experiments. X.L. analyzed the data, performed the model simulation and wrote the manuscript. Y.T. and Y.C. revised the paper.

Funding: This research was funded by the Special Fund for Water Resources Scientific Research in the Public Welfare Profession of China (No. 201401024), the Young Scientists Fund of the National Natural Science Foundation of China (No. 41501046), the Water Resource Science and Technology Innovation Program of Guangdong Province (No. 2016-14).

Conflicts of Interest: The authors declare no conflict of interest. 


\section{Appendix A}

HIMS (Hydro-Informatic Modelling System)

HIMS was developed to facilitate water resources management and water environment protection. It includes a hydrologic information system (HIS) and a hydrologic model library (HML). The HIS provides functions to deal data with different sources and obtain geographical characters from DEM by integrating with GIS and remote sensing. The HML incorporated most of the commonly used methods and some new models developed by Liu's team in modelling runoff generation and flow routing. These include hydraulic methods and hydrologic methods whether physical, statistical, or conceptual one. In this study, the surface runoff model was LCM model, which is a conceptual model developed by Liu et al. (1965) [29] and has been the core module for runoff calculation in HIMS. Other models dealing with sediment, water quality, ecology, and agriculture can also be incorporated into the framework. Based on spatial topological relationships among the channel network, HIMS divides a catchment into different sub-basins with different soil, vegetation and land use properties. Each sub-basin can include a channel, and sub-basins are linked through stream network. The main parameters of HIMS model are shown in Table A1.

Table A1. Model parameters and range.

\begin{tabular}{ccc}
\hline Parameters & Meaning & Range \\
\hline$W_{\mathrm{sm}}$ & maximum soil storage capacity & $50 \sim 1200$ \\
$R^{*}$ & parameter related to land use and soil moisture & $0 \sim 2$ \\
$r^{*}$ & parameter related to land use and soil moisture & $0 \sim 1$ \\
$L_{\mathrm{a}}$ & coefficient of sub-surface runoff & $0 \sim 1$ \\
$R_{\mathrm{c}}$ & coefficient of recharge into the groundwater & $0 \sim 1$ \\
$\varepsilon$ & actual evapotranspiration index & $0 \sim 10$ \\
$K_{\mathrm{b}}$ & coefficient of base flow & $0 \sim 1$ \\
$C_{1}, C_{2}$ & Muskingum model parameters & $0 \sim 1$ \\
\hline
\end{tabular}

* More details about LCM model can be found in Li et al. (2015) [30].

HIMS has been widely tested for catchments under different natural conditions in both northern and southern China, Australia, and some parts of the United States. The modeling results were satisfactory. The HIMS system have been applied to simulate hourly streamflow in small and medium watersheds and daily runoff in medium and large watersheds in case studies [20,31]. The system is still developing and is available by contacting the Key Laboratory of Water Cycle and Related Land Surface Processes.

\section{References}

1. Hrachowitz, M.; Savenije, H.H.G.; Blöschl, G.; McDonnell, J.J.; Sivapalan, M.; Pomeroy, J.W.; Arheimer, B.; Blume, T.; Clark, M.P.; Ehret, U. A decade of Predictions in Ungauged Basins (PUB)—A review. Hydrol. Sci. J. 2013, 58, 1198-1255. [CrossRef]

2. Sivapalan, M.; Takeuchi, K.; Franks, S.W.; Gupta, V.K.; Karambiri, H.; Lakshmi, V.; Liang, X.; McDonnell, J.J.; Mendiondo, E.M.; O'Connell, P.E.; et al. IAHS decade on predictions in ungauged basins (PUB), 2003-2012: Shaping an exciting future for the hydrological sciences. Hydrol. Sci. J. 2003, 48, 857-880. [CrossRef]

3. Pumo, D.; Conti, F.; Viola, F.; Noto, L. An automatic tool for reconstructing monthly time-series of hydro-climatic variables at ungauged basins. Environ. Model. Softw. 2017, 95, 381-400. [CrossRef]

4. Qamar, M.U.; Azmat, M.; Cheema, M.J.M.; Shahid, M.A.; Khushnood, R.A.; Ahmad, S. Model swapping: A comparative performance signature for the prediction of flow duration curves in ungauged basins. J. Hydrol. 2016, 541, 1030-1041. [CrossRef]

5. Gibbs, M.S.; Maier, H.R.; Dandy, G.C. A generic framework for regression regionalization in ungauged catchments. Environ. Model. Softw. 2011, 27, 1-14. [CrossRef] 
6. El-Hames, A.S. An empirical method for peak discharge prediction in ungauged arid and semi-arid region catchments based on morphological parameters and SCS curve number. J. Hydrol. 2012, 456, 94-100. [CrossRef]

7. Pumo, D.; Viola, F.; Noto, L. Generation of natural runoff monthly series at ungauged sites using a regional regressive model. Water 2016, 8, 209. [CrossRef]

8. Falkenmark, M.; Rockström, J. The new blue and green water paradigm: Breaking new ground for water resources planning and management. J. Water Resour. Plan. Manag. 2006, 132, 129-132. [CrossRef]

9. Liu, C.; Wei, Z. Agricultural Hydrology and Water Resources in the North China Plain; Science Press: Beijing, China, 1989.

10. You, M.; Wang, H. Assessment of Field Soil Water Reources; China Meteorological Press: Beijing, China, 1996.

11. Xia, J.; Pan, X.; Chen, X.; Liu, Y. A review of soil water resource research and application in China. IAHS Publ. Ser. Proc. Rep. 2007, 315, 215-220.

12. Rockström, J.; Falkenmark, M.; Karlberg, L.; Hoff, H.; Rost, S.; Gerten, D. Future water availability for global food production: The potential of green water for increasing resilience to global change. Water Resour. Res. 2009, 45. [CrossRef]

13. Wang, H.; Yang, G.; Jia, Y.; Wang, J. Connotation and assessment index system of soil water resources. J. Hydraul. Eng. 2006, 37, 389-394.

14. Zhang, W.; Zhang, P.; Li, J.; Ma, Y. Evaluation of soil water resource and study of ecological recovery in Loess Plateau. Yellow River 2012, 34, 100-102.

15. Shen, R. Investigation on conception and evaluation method of soil water resources. J. Hydraul. Eng. 2008, 39, 1395-1400.

16. Liu, L.; Xu, X.; Wang, H.; Yin, J. Advances in soil resource assessment. J. Beijing Norm. Univ. 2009, Z1, 621-625.

17. Anoh, K.A.; Koua, T.J.J.; Eblin, S.G.; Kouamé, K.J.; Jourda, J.P. Modelling freshwater availability using SWAT model at a catchment-scale in ivory coast. J. Geosci. Environ. Protect. 2017, 5, 70-83. [CrossRef]

18. Smakhtin, V.; Revenga, C.; Döll, P. A pilot global assessment of environmental water requirements and scarcity. Water Int. 2004, 29, 307-317. [CrossRef]

19. National Development and Reform Commission of the People's Repeblic of China; Ministry of Foreign Affairs of the People's Repeblic of China; Ministry of Commerce of the People's Repeblic of China. Vision and proposed actions outlined on jointly building Silk Road Economic Belt and 21st-Century Maritime Silk Road. Available online: http:/ / www.ndrc.gov.cn/gzdt/201503/t20150328_669091.html (accessed on 17 January 2018).

20. Liu, C.; Wang, Z.; Zheng, H.; Zhang, L.; Wu, X. Development of hydro-informatic modelling system and its application. Sci. China Ser. E Technol. Sci. 2008, 51, 456-466. [CrossRef]

21. Fujian Province Pingtan County Local Records Committee. Pingtan County Local Records; China Local Records Publishing: Beijing, China, 2000.

22. Ministry of Land and Resources, People's Republic of China. The Second National Land Survey Technical Regulations; TD/T 1014-2007; Ministry of Land and Resources, People's Republic of China: Beijing, China, 2007.

23. Committee of Construction and Traffic in Shanghai City. Code for Design of Outdoor Wastewater Engineering (GB50014-2006); China Planning Press: Beijing, China, 2006.

24. Wang, Z.; Zheng, H.; Liu, C. A modular framework of distributed hydrological modeling system: HydroInformatic modeling system. HIMS. Prog. Geogr. 2005, 24, 109-115.

25. Orth, D.J.; Leonard, P.M. Comparison of discharge methods and habitat optimization for recommending instream flows to protect fish habitat. River Res. Appl. 1990, 5, 129-138. [CrossRef]

26. Yao, S.; Guo, Z.; Ren, J.; Wang, S.; Liu, H. On calculation of amount of available surface water. J. Zhejiang Univ. 2005, 31, 479-482.

27. Feng, Q.; Wang, H. Discussion on evaluation method of soil water resource. J. China Hydrol. 1990, 4, $28-32$.

28. Ji, S.; Unger, P.W. Soil water accumulation under different precipitation, potential evaporation, and straw mulch conditions. Soil Sci. Soc. Am. J. 2001, 65, 442-448. [CrossRef] 
29. Liu, C.; Hong, B.; Zeng, M.; Cheng, Y. An experimental study on relation of rainfall forecasting in the Loess Plateau. Sci. Bull. 1965, 2, 158-161.

30. Li, J.; Liu, C.; Wang, Z.; Liang, K. Two universal runoff yield models: SCS vs. LCM. J. Geogr. Sci. 2015, 3, 311-318. [CrossRef]

31. Liu, C.; Wang, Z.; Yang, S.; Sang, Y.; Liu, X.; Li, J. Hydro-Informatic Modeling System: Aiming at water cycle in land surface material and energy exchange processes. Acta Geogr. Sin. 2014, 5, 579-587. 